\title{
A USEFUL MANOEUVRE FOR PREVENTION OF ASPIRATION DURING "CRASH" INDUCTIONS
}

\author{
K. W. TuRNaulL, B.A.sc., M.D."
}

PREvENTION OF aspiration when anaesthetic techniques which obtund laryngeal reflexes are used is a daily challenge to the anaesthetist handling obstetrical cases or emergency surgery. In the situation where awake intubation is elected or a "crash induction" is chosen, the following manoeuvre is used to save time and prevent entry of acidic gastric fluids, food particles, and other foreign bodies into the lungs. It is assumed that (1) prophylactic antacids, ${ }^{1}$ (2) posture, ${ }^{2}$ (3) gastric tubes, ${ }^{3}$ (4) Sellick's Manoeuvre ${ }^{4}$ and a cuffed endotracheal tube will all be used to minimize the chance of aspiration.

The equipment (see Figure 1) required is an endotracheal tube with a distensible elastic or rubber cuff and pilot balloon, two "bulldog" (or equal) clips and the usual cuff inflation syringe and endotracheal tube connectors.

The use of preoxygenation for three minutes, then a small dose $(1 \mathrm{cc})$ of a competitive blocker (eg. d-tubocurarine, Gallamine) prior to a sleep dose of

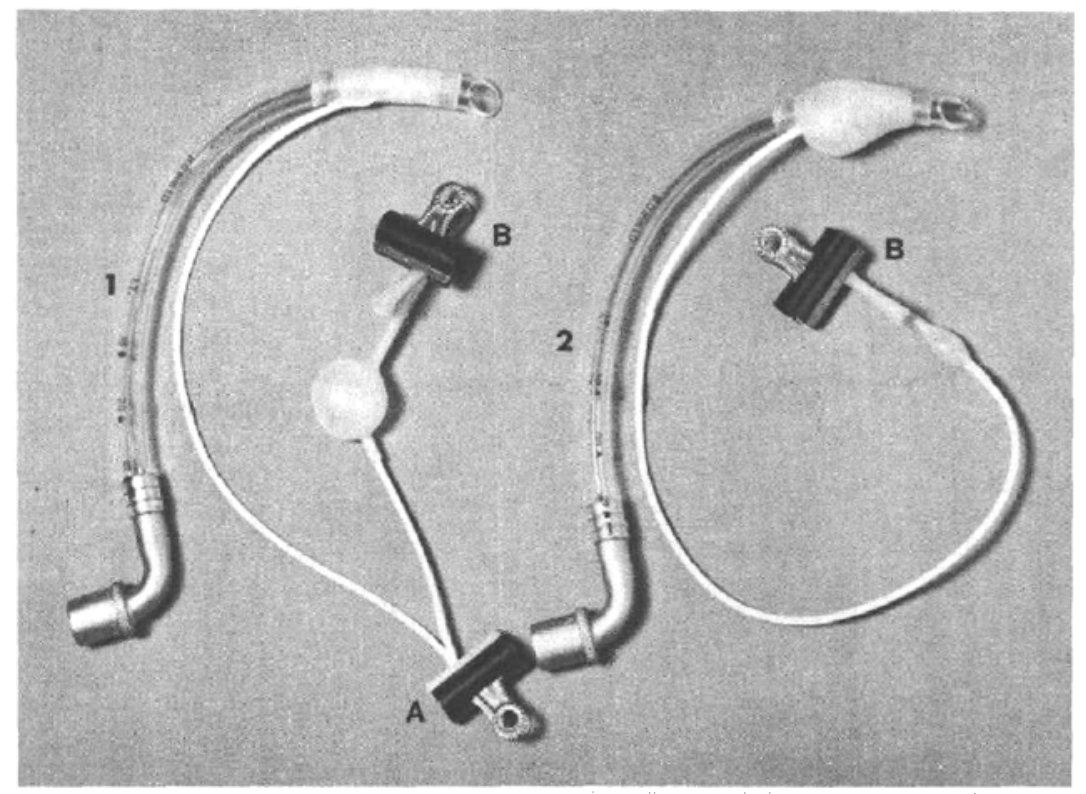

Ficure 1. Endotracheal tube No. 1 with "bulldog" proximal (A) to cuff and distal to pilot balloon (B) in place. Endotracheal tube No, 2 has an inflated culf after removal of "bulldog" $\mathrm{A}$.

- Department of Anaesthesia, Vaucouver Ceneral Hospital.

Canad, Anaesth. Soc. J, vol. 19, no 1, January 1972 
pentothal (e.g. $3-5 \mathrm{mg} / \mathrm{kg}$ ) is recommended. ${ }^{2}$ The role of the competitive blocker is to prevent fasciculation thus minimizing the chance of intragastric pressure increase from the use of the depolarizing blocker leading to regurgitation."

Fifteen to twenty seconds (circulation time in normal patients) after the succinylcholine a laryngoscope is used to expose the larynx and cords and immediate intubation followed by removal of the proximal "bulldog" is done to ensure a sealed but patent airway. The advantage is speed. The principal disadvantage is the lack of control over tracheal pressure. This disadvantage can be overcome with judicious adjustment of cuff pressure when the risk of aspiration is diminished.

\section{REFERENCES}

1. Thyzor, G. \& Payse-Davies, J. P. The Prophylactic Use of Antacids in the Prevention of the Acid-Pulmonary-Aspiration Syndrome (Mendelson's Syndrome). Lancet, 1: 288 (1966).

2. Lae, J. A. Atmonson, R. S. A Synopsis of Anaesthesia. Bristol, Wright \& Sons, p. 510 (1968)

3. Culver, G. A, Maxce, Major H. P., Be Becher, H. K. Frequency of Aspiration of Gastric Contents by the Lungs Durring Anaesthesia. Ann. Surg, 133: 289 (1951).

4. Seruxck, B. A. Cricoid Pressure to Control Regurgitation of Stomach Contents During Induction of Anaesthesia. Lancet, 2: 404 (1961).

5. MHLER, R. D. Inhibition of Succinylcholine-Induced Increased Intragastric Pressure by Non-depolarizing Muscle Relaxants in Abstracts of Scientific Papers. 1969 Annual Meeting, The American Society of Anesthesiologists. 